\title{
The hematology profiles of children affiliated with epilepsy at Sanglah Hospital after receiving valproic acid therapy
}

\author{
Yanitama Putri, Dewi Sutriani Mahalini and I Gusti Ngurah Made Suwarba
}

Department of Child Health, Medical Faculty of Udayana University, Sanglah Hospital, Denpasar, Bali, Indonesia.

Accepted 4 September, 2019

\begin{abstract}
Epilepsy is the most common neurological diseases with a high prevalence in the world. Valproic acid as the first line therapy has some adverse effects on hematology field. However, the data about hematological effects from the use of valproic acid as therapy in children with epilepsy is currently still limited. This is a cross sectional study to describe the hematology profile of children with epilepsy treated by valproic acid at Sanglah Hospital. Data collection was done during February to May 2018. We report 58 subjects of children with epilepsy treated with valproic acid at Sanglah Hospital. The mean age is 4.47 years, $60 \%$ are male. About $79.3 \%$ were generalized seizure, and $89 \%$ from them were tonic clonic type. Fifty percent of partial seizure were partial complex epilepsy. Forty-six EEG results $(79.3 \%)$ were abnormal. We found 4 cases $(0.07 \%)$ of thrombocytopenia at dose of $30 \mathrm{mg} / \mathrm{kg} /$ day and the others at $25 \mathrm{mg} / \mathrm{kg} /$ day. The thrombocyte level recovered after the valproic acid discontinued. We found 29 cases of anemia, $86.2 \%$ with mild anemia and others $13.2 \%$ with moderate anemia. Most of the anemia cases were found after 12 months of treatment. In conclusion, the use of valproic acid as a therapy indicates the role of drug dose and timerelated spectrum of hematology disorders that ranges from thrombocytopenia to anemia. Routine laboratory evaluation is necessary, especially after 12 months of treatment with valproic acid and at a dose of valproic acid $25 \mathrm{mg} / \mathrm{kg} /$ day or more.
\end{abstract}

Keywords: Children, epilepsy, hematology profile, valproic acid.

${ }^{*}$ Corresponding author. E-mail: dryanitama01@gmail.com. Tel: +6282145389833.

\section{INTRODUCTION}

Epilepsy is considered in a person if they meet the following conditions such as (1) At least two unprovoked (or reflex) seizure occurring greater than 24 hours apart, (2) One unprovoked (or reflex) seizure and a probability of further seizures similar to the general recurrence risk (at least $60 \%$ ) after two unprovoked seizures, occurring over the next 10 years (3) Diagnosis of an epilepsy syndrome (NICE, 2012; Mehmood et al., 2014). Epilepsy is the most common neurological diseases and one of the non-infectious diseases with a high prevalence in the world that is marked by periodic seizures that cannot be predicted (NICE, 2012). Data from the World Health Organization (WHO) shows that there are more than 50 million patients with epilepsy in the world today and $85 \%$ dwelling place in developing countries. WHO also said that around 8 from 1000 children in the world suffer from epilepsy, in Indonesia there are around 1.8 million children with epilepsy, with incidents of 5.3 percent and still need a long-term treatment (Hawari, 2010). Epilepsy is a condition caused by the change in the spreading of electrical explosions in the neurons cortex (WHO, 2006; NICE, 2012). Epilepsy is diagnosed clinically and can be prompted for electrical changes in the brain through an electroencephalography (EEG) examination (Nordli, 2017). Detailed analysis of epileptiform abnormalities may distinguish focal from generalized processes. EEG allows recognition of subtle and non-convulsive seizures, can help to identify antiepileptic drug (AED) toxicity, and 
useful in selecting patients for AED withdrawal after remission of seizures. Non-epileptiform abnormalities can include focal or generalized slow-wave activity or asymmetries of frequency or voltage. The principal EEG finding that indicates a susceptibility to epileptic seizures is epileptiform activity in form of spikes, sharp waves, or spike-wave discharge (Nordli, 2017).

Two thirds of children with epilepsy is active in the condition of the disease controlled with satisfying uses of AED (Goldenberg, 2010; NICE, 2012). When still allows, a monotherapy is a recommended treatment strategy. Many side effects of AED is related to dosage and occurs related to the dose of therapy. To minimize the effects, it should start with a low dose and slowly propagated up to the minimum dosage that can control seizures (WHO, 2006; Goldenberg, 2010).

Valproic acid is a broad spectrum anticonvulsant that approved its use since 1967 and used as therapy seizures and other psychiatric condition (Fagundes, 2008). Valproic acid is the first line therapy to resolve the common type of seizure such as tonic clonic, myoclonic, atonic, and absent (WHO, 2006; Fagundes, 2008; NICE, 2012). Valproic acid can be used as a monotherapy or additional therapy for seizures partial types and can be useful in patients with mixed types of seizures (Fagundes, 2008). Valproic acid has a number of side effects that requires an evaluation of the effectiveness and safety in its use as anti-epileptic drugs (Fagundes, 2008; Verroti et al., 2014). The side effects that most happens is hepatobiliary system disorders (increasing of hepatic enzymes), gastrointestinal disease (nausea and diarrhea), the central nervous system disease (hyperactivity and behavior disorder), metabolism disturbances (hyperammonemia), an increasing of bodyweight, hematological disorders (thrombocytopenia, anemia, pancytopenia, neutropenia, leucopenia) (Chateauvieux et al., 2010; Kompally, 2015). Based on the side effects of hematological profile, the incidence of thrombocytopenia that induced by valproic acid as a side effect is by $19 \%$ prevalence in the world (Mehmood, 2014).

Data from the side effects, especially hematological effects from the use of valproic acid as therapy in children with epilepsy at Sanglah Hospital in Denpasar, Bali is currently still limited. This study is done to describe about the hematology profile of children with epilepsy treated by valproic acid at Sanglah Hospital.

\section{MATERIALS AND METHODS}

This research is a cross sectional study to describe the hematology profile of children with epilepsy treated by valproic acid at Sanglah Hospital. The data is obtained from medical record of children with epilepsy at Sanglah Hospital Denpasar which was recorded in 2016 until the number of samples is achieved. Data collection was done from February to May 2018.

The target population is children with epilepsy in Sanglah Hospital Denpasar, Indonesia. Samples selected by consecutive sampling. The inclusion criteria is children age 1 month up to 12 years suffered from epilepsy and uses valproic acid as the AED, both monotherapy or combination with other AED (combination therapy or polytherapy). We excluded samples of those children also diagnosed with malignancy, hematological disorders such as Idiopathic Thrombocytopenic Purpura(ITP), and similar substances, and if the data is not complete.

This research has received permission from the ethical committee of the Medical Faculty of Udayana University with number of 195/UN.14.2/KEP/2018. This research data include characteristics of the subject such as age, gender, nutritional status, EEG finding, duration of Valproic acid treatment, and type of treatment. Hematology profile of the patients including hemoglobin, leucocyte, thrombocyte, and neutrophil was done. We obtained the minimal sample size in this research is 58 samples based on the samples formula of single proportion of descriptive data (incidence of thrombocytopenia in children with epilepsy treated with valproic acid in previous study $(P=19 \%)$ and precise values $(d=10 \%)$. After the feasibility assessment samples, 58 cases that meet the criteria of inclusion and exclusion research samples were analyzed statistically.

Epilepsy is a clinical diagnosis of the seizures a person as the following condition such as (1) At least two unprovoked (or reflex) seizure occurring greater than $24 \mathrm{~h}$ apart, (2) One unprovoked (or reflex) seizure and a probability of further seizures similar to the general recurrence risk (at least 60\%) after two unprovoked seizures, occurring over the next 10 years (3) Diagnosis of an epilepsy syndrome. Gender is male or female according to phenotype. Age at diagnosed is a chronological age of the children when diagnosed epilepsy at first time. The type of seizure is types of seizures attack that are considered clinically at the first time diagnosed. Those are grouped into general seizures (tonic, clonic, tonic-clonic, absence, myoclonic, atonic) and partial seizures (partial simple, partial complex partial to general). Electroencephalography (EEG) is the result of the electrical recording of the brain of epilepsy patients which are interpreted as normal and abnormal. Duration of treatment with valproic acid is the duration of taking valproic acid as the treatment, counted from the first time consuming until the time of the data collection started (minimum use of valproic acid is for 6 months). Type of medicines that are used are divided into a monotherapy and combination therapy or polytherapy. A monotherapy is treatment with valproic acid alone, while polytherapy is a combination with other AED. The results of the laboratory during treatment is the result of the examination of the blood of the patient is recorded in the medical record or the recording of electronic laboratory at Sanglah Hospital or in a laboratory outside of the Sanglah Hospital in the form of complete blood count. Anemia is hemoglobin $(\mathrm{Hb})$ less than normal limit according to the age, mild anemia defined if $\mathrm{Hb}$ less than 9 $\mathrm{g} / \mathrm{dl}$, moderate anemia if $\mathrm{Hb}$ beetwen 6 and $9 \mathrm{~g} / \mathrm{dl}$, severe anemia is less than $6 \mathrm{~g} / \mathrm{dl}(\mathrm{g} / \mathrm{dl})$. Thrombocytopenia is the level of platelets less than $150\left(10^{3} / \mathrm{ul}\right)$.

All appropriate data was then collected and processed using computer programs. The data were presented descriptively. Category variables described in the amount of $(n)$ and percentage (\%).

\section{RESULTS}

From 58 subjects, the age ranges from $<12$ months up to 12 year old with most of them (19\%) are $<12$ months old, followed by 1 to 2 years of age (13.8\%) in the second place, with the mean of age is about 4.47 year. Sixty percent of them are male (35 subjects, 60\%). Regarding to the nutritional status, well nourish 45 subjects $(77.6 \%)$, 
malnourish 13 subjects (22.4\%). About forty-six subjects $(79.3 \%)$ are with generalized seizure, of which 41 subjects (89\%) were with tonic clonic type of generalized epilepsy. From $12(20.7 \%)$ subjects of partial seizure, about six of them $(50 \%)$ were defined as partial complex epilepsy. EEG finding was found that 46 results $(79.3 \%)$ were abnormal, and 12 others (20.7\%) were normal EEG. Most of the subjects were treated with AED as monotherapy, 30 subjects $(51.7 \%)$ has been treated for 12 months, 12 subjects (20.7\%) for 6 months, 10 subjects (17.2\%) for 24 months, and 6 subjects $(10.3 \%)$ for 18 months (Table 1, Figure 1).

Regarding to the hematology profile, in means, all of the subjects are within normal range (Table 2), we have no found evidence of leucopenia nor neutropenia in our subjects (normal leucocyte count: 6 to $14 \times 10^{3}$ cells $/ \mu$; normal $\mathrm{Hb}$ content: 12 to $16 \mathrm{~g} / \mathrm{dl}$; normal cell count of thrombocytes: $140.0 \times 10^{3}$ to $440.0 \times 10^{3} / \mu \mathrm{l}$; normal neutrophil count: 1.1 to $\left.6.6 \times 10^{3} / \mu \mathrm{l}\right)$. However, we found mild anemia in 25 subjects and moderate anemia in 4 subjects. Most of them were found in 12 months of treatment. Our data showed that, regarding to nutritional status, most of the patient with anemia were well nourish (19 subject, 65.5\%), and others 10 subject (34.4\%) were malnourish.

Regarding to the thrombocyte count, we found 4 cases of thrombocytopenia. The scatter diagram of the thrombocyte above has been showed that the incidence and severity of thrombocytopenia is related to the dose and duration of the valproic acid treatment. The thrombocyte started to decrease on 12 month of treatment and at the range dose $25 \mathrm{mg} / \mathrm{kg} /$ day. From 4 cases of thrombocytopenia, 2 subjects had thrombocytopenia at valproic acid dose of $30 \mathrm{mg} / \mathrm{kg} /$ day and the others two subjects were at dose $25 \mathrm{mg} / \mathrm{kg} / \mathrm{day}$ of valproic acid. The scatter line chart confirmed that the thrombocyte level rising up immediately after the valproic acid discontinued (Figure 2).

\section{DISCUSSION}

This research was bout the hematology profile of children with epilepsy treated by valproic acid at Sanglah Hospital. Most of the subjects was male, $<12$ months old, with the mean of age was 4.47 year. The same finding was reported by Suwarba (2011) who studied the characteristic of children with epilepsy at Sanglah Hospital in January 2007 until December 2010. He has been reported that the onset of epilepsy in children $46 \%$ were at the age of $<1$ year old. This finding also supported by the others two studies at Children and Women Harapan Kita Hospital Jakarta by Tjandrajani et al. (2012) and dr. Soetomo Hospital Surabaya by Andriati et al. (2016) which also found that the incidents of epilepsy in children was on average of age 1 to 5 years old were 38.3 and $45.63 \%$, with about 53.9 and $71.84 \%$
Table 1. Subjects characteristics.

\begin{tabular}{lc}
\hline Variables & $\mathrm{N}=58(\%)$ \\
\hline Gender, $\mathrm{n}$ & $35(60)$ \\
Male & $23(40)$ \\
Female & \\
Nutrition status, $\mathrm{n}$ & $13(22.4)$ \\
Malnourish & $45(77.6)$ \\
Well nourish & \\
& \\
Type of seizure, $\mathrm{n}$ & $12(20.7)$ \\
Partial & $46(79.3)$ \\
Generalized & \\
EEG finding, $\mathrm{n}$ & \\
Normal & $12(20.7)$ \\
Abnormal & $46(79.3)$ \\
Type of therapy, $\mathrm{n}$ & \\
Monotherapy & \\
Polytherapy & \\
Duration of treatment, $\mathrm{n}$ & $51(88)$ \\
6 month & $7(12)$ \\
12 month & \\
18 month & \\
\hline
\end{tabular}

were male, respectively.

Epilepsy is a clinical diagnosis. EEG should be performed only to support a diagnosis of epilepsy in whom the clinical history suggests that the seizure is likely to be epileptic in origin. The EEG should not be used to exclude a diagnosis of epilepsy in a child (NICE, 2012). Regarding to the type of seizure, most common type was tonic clonic generalized seizure. Most of the EEG was abnormal finding. This data was supported by study of Suwarba (2011) that found most of the seizure types were tonic clonic generalized seizure with abnormal EEG finding on the symptomatic epilepsy. Tjandrajani et al. (2012) reported that mostly generalized type of seizure was found in subjects with abnormal EEG finding.

AED therapy should only be started once the diagnosis of epilepsy is confirmed (NICE, 2012). It is recommended that children, young people and adults should be treated with a single AED (monotherapy) wherever possible (NICE, 2012). If the initial treatment is unsuccessful, then monotherapy using another drug can be tried, the dose need to built up to an adequate or maximum tolerated dose and then the first drug should be tapered off slowly (Goldenberg, 2010; NICE, 2012). It is also recommended that combination therapy (adjunctive or 'add-on' therapy) should only be considered when attempts at 


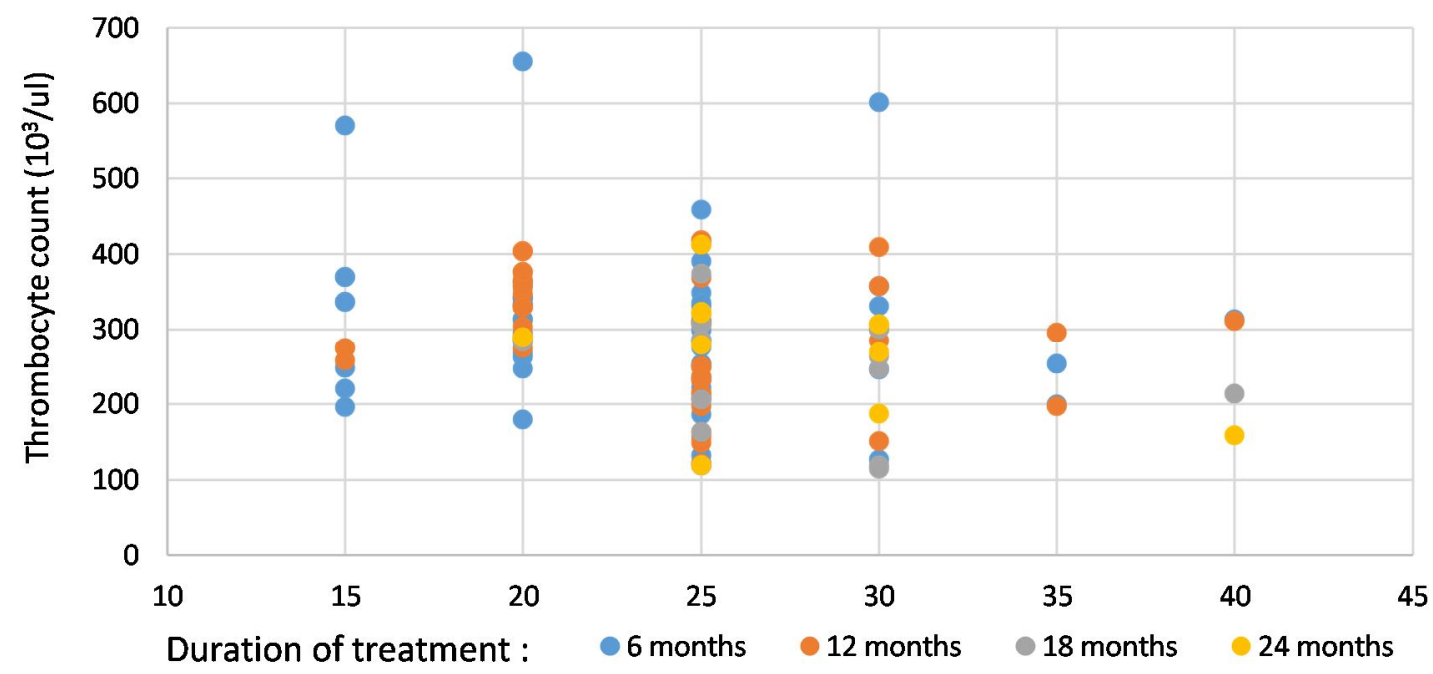

Figure 1. Distribution of the thrombocyte count according to the dose and duration of valproic acid treatment. *Note: normal range of thrombocyte count is $140.0 \times 10^{3}$ to $440.0 \times 10^{3} / \mu$ l.

Table 2. Hematology profile based on duration of valproic acid treatment.

\begin{tabular}{lcccc}
\hline & \multicolumn{4}{c}{ Means } \\
\cline { 2 - 5 } & $\mathbf{6}$ months & $\mathbf{1 2}$ months $^{*}$ & $\mathbf{1 8}$ months $^{*}$ & $\mathbf{2 4}$ months $^{*}$ \\
\cline { 2 - 5 } & $\mathbf{n}=\mathbf{5 8}$ & $\mathbf{n}=\mathbf{4 6}$ & $\mathbf{n}=\mathbf{1 6}$ & $\mathbf{n}=\mathbf{1 0}$ \\
\hline Leucocyte $\left(10^{3} / \mathrm{ul}\right)$ & 9.5524 & 9.2074 & 9.5787 & 8.0310 \\
Hemoglobin $(\mathrm{g} / \mathrm{dl})$ & 12.2712 & 12.3343 & 13.0050 & 12.7920 \\
Thrombocyte $\left(10^{3} / \mathrm{ul}\right)$ & 290.1147 & 282.6407 & 258.3750 & 257.7200 \\
Neutrophil\# $\left(10^{3} / \mathrm{ul}\right)$ & 4.1079 & 3.8576 & 4.4763 & 3.1980 \\
\hline
\end{tabular}

*Duration of valproic acid treatment.

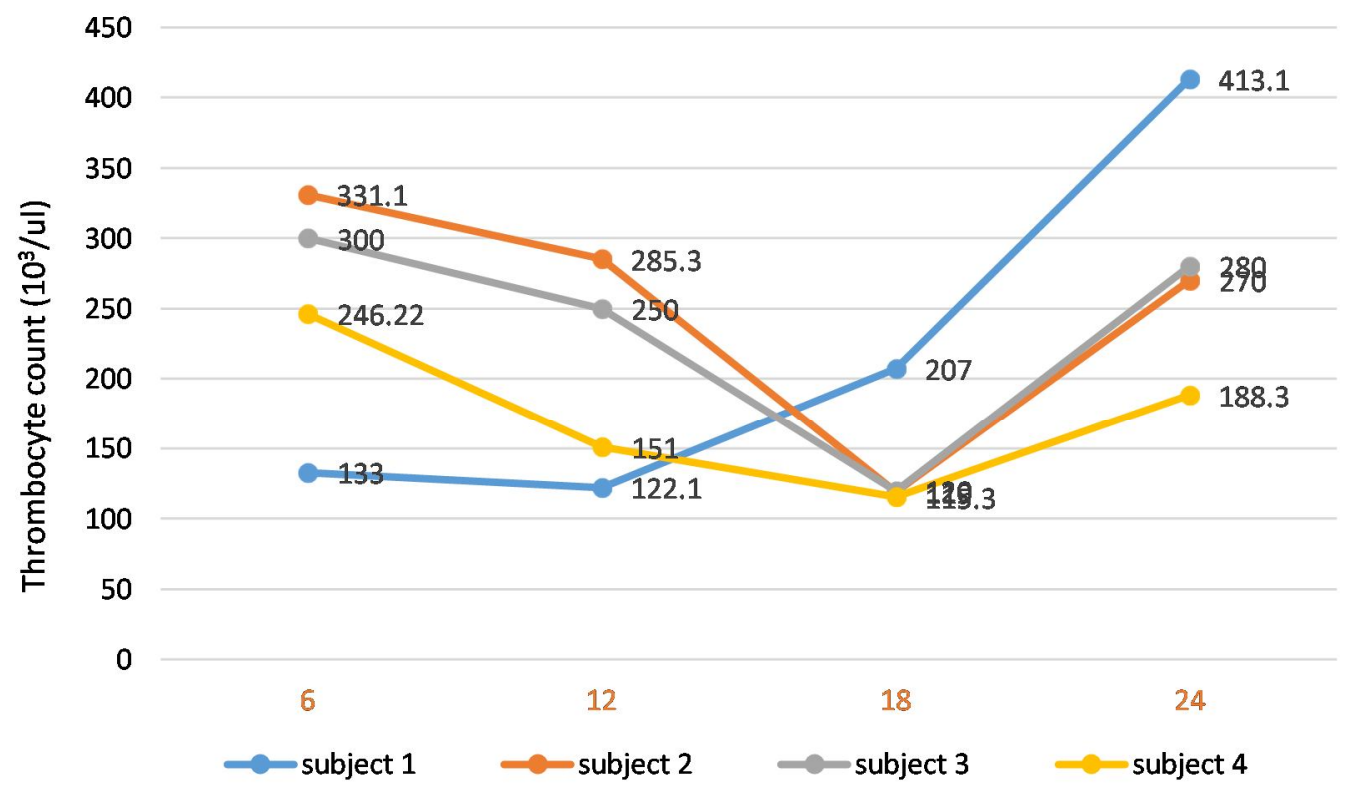

Note: - $X$ axis, duration of valproic acid treatment;- $Y$ axis, thrombocyte count

Figure 2. Thrombocyte count of 4 subjects with thrombocytopenia based on duration of valproic acid treatment (6 months, 12 months, 18 months and 24 months) as monotherapy anti epileptic drug. 
monotherapy with AEDs have not resulted in seizure freedom (Goldenberg, 2010). There is a strong recommendation in Europe and the USA that valproic acid should be considered as a first line treatment in generalized, partial and other epilepsies (WHO, 2006). In our study, most of the subjects were treated with AED as monotherapy of valproic acid, seventh others were in combination with carbamazepine. Adverse drug reactions due to valproate range from mild to life threatening effects like gastrointestinal (GI) disturbance, nausea, vomiting, weight gain, sedation, acute liver disease, hepatotoxicity, pancreatitis, effects on coagulation, thrombocytopenia, hyperglycemia and insulin resistance, hyperammonemia, sedation, alopecia, and tremor. We found one subject with significant increasing of the body weight after having the valproic acid treatment for about 6 months. A study at Warangal India by Kompally et al. (2015), also found small event of the weight gain after valproic acid treatment. They found only $3.84 \%$ patients with a drastic increase in their weight after 1 year of initiation therapy with valproic acid.

Many AEDs are associated with hematological disorders with a spectrum of hematological abnormalities that ranges from mild thrombocytopenia or neutropenia to anemia, red cell aplasia, until bone marrow failure (Verroti et al., 2014). Thrombocytopenia is a serious adverse effect of valproic acid. It may be responsible for dose reduction and even discontinuation of this important drug (Andrianti et al., 2016). Mechanism of thrombocytopenia in patients receiving valproic acid is not fully understood, immune mediated peripheral destruction of platelets has been attributed to it. High doses of valproic acid have also been associated with thrombocytopenia through bone marrow suppression. This can explain increased tendency of thrombocytopenia with higher doses of valproic acid (Nasrullah et al., 2015). Thrombocytopenia is thought to occur in between 5 and $40 \%$ of children receiving valproate (Star et al., 2014). Mehmood et al. (2014) in Pakistan has been reported the incidence of thrombocytopenia in their patient after taking valproate at least 6 months and at least $30 \mathrm{mg} / \mathrm{kg} /$ day of valproic acid dose. About $19.3 \%$ children had thrombocytopenia. The other study by Nasreddine and Beydoun (2008) at Libanon has been found that $17.7 \%$ patients with a range of age 10 to 64 years experienced of thrombocytopenia (platelet count $\leq 100$. 000/ $\mu \mathrm{l}$ ). Thrombocytopenia occurred on average 82 days (range 38 to 170 days) after exposure to valproic acid. The frequency of thrombocytopenia increased with higher plasma valproic level. No patient with thrombocytopenia required transfusions or died because of low platelet count. All patients with thrombocytopenia recovered from this adverse event after dose reduction or discontinuation of valproic acid (Nasreddine et al., 2008). We reported $6.8 \%$ thrombocytopenia. The incidence and severity of thrombocytopenia is showed to be related with the duration of the valproic acid treatment. The thrombocyte started to decrease on 12 month of treatment and at dose dose range start to reach the $25 \mathrm{mg} / \mathrm{kg} /$ day. From those 4 cases, two subjects had thrombocytopenia at drug dose of $30 \mathrm{mg} / \mathrm{kg} /$ day and the others two subjects were at dose $25 \mathrm{mg} / \mathrm{kg} /$ day of valproic acid. The thrombocyte level seems to rising up immediately after the valproic acid discontinued. In contrast to this study, Kumar et al. (2014) at India has been reported that there was no thrombocytopenia in their study.

The use of valproic acid in children with epilepsy also has others form of side effect on the hematology profile, including anemia, leukopenia and neutropenia (Verroti et al., 2014). The incidence of anemia in epilepsy patient using valproic acid is quite rare (Star et al., 2014). However, from some cases of epilepsy, the evidence of anemia in patients using valproic acid was higher in children rather than in adult. Ghosh et al. (2017) at India has been reported the use of valproic acid is associated with a nine-fold risk of aplastic anemia, based on the case after 2 month of using valproic acid in dose of 20 $\mathrm{mg} / \mathrm{kgbodyweight} /$ day (Ghosh et al., 2017). Another study from Kaczorowska-Hac et al. (2012) reported the case of mild anemia in 13 years old children with epilepsy after having 12 month of valproic acid as the AED. In our study, regarding to the incidence of anemia, the incidence and severity of anemia is related to the duration of the valproic acid treatment. We found 29 cases of anemia, range from 25 subjects with mild anemia and others 4 subjects with moderate anemia. Most of them were found in 12 months of treatment. Our data showed that, regarding to nutritional status, most of the patients with anemia were well nourished (65.5\%), and others $34.4 \%$ were malnourish. Neither leukopenia nor neutropenia were found in our study, in contrast, Kaczorowska-Hac et al. (2012) has been reported that $26 \%$ of their subjects experienced of leukopenia after treated with valproic acid.

\section{Conclusion}

Valproic acid is one of the AEDs that are generally regarded as a first-choice agent for most forms of symptomatic and idiopathic generalized epilepsies. It is showed as drug dose and time dependent-associated with a spectrum of hematology abnormalities that ranges from thrombocytopenia to anemia. We suggestions all patients with hematology abnormalities recovered immediately from this adverse event after dose reduction or discontinuation of valproic acid. Routine laboratory evaluation is necessary, especially after 12 months of treatment with valproic acid and at a dose of valproic acid $25 \mathrm{mg} / \mathrm{kg} /$ day or more. A prospective observational with control study is recommended in further for better analysis and evaluation of the hematology profile of children with epilepsy treated with valproic acid. 


\section{ACKNOWLEDGEMENTS}

Special thanks to all the outpatient staff especially neurology division in a perfect way to complete the registration record of epilepsy patient, also to medical record unit staff to provide the medical record in collecting the research sample.

\section{REFERENCES}

Andrianti PT, Gunawan PI, Hoesin F, 2016. Profil epilepsi anak dan keberhasilan pengobatannya di RSUD dr. Soetomo tahun 2013. Sari Pediatri, 18(1): 34-39.

Chateauvieux S, Morceau F, Dicato M, 2010. Molecular and therapeutic potential and toxicity of valproic acid. J Biomed Biotechnol, 1-18.

Fagundes SBR, 2008. Valproic acid: Review. Rev Neurosci, 16(2): 130-136.

Ghosh A, Sharma S, Mukhopadhyay S, 2017. Catastrophic presentation of sodium valproate induced pure red cell aplasia in a child with absence seizure. J Hematol Thrombo Dis, 5: 1-3.

Goldenberg MM, 2010. Overview of drugs used for epilepsy and seizures: Etiology, diagnosis and treatment. P\&T, 35(7): 393-415.

Hawari I, 2010. Epilepsi di Indonesia. YEI. Available from: http://www.ina-epsy.org/2010/08/epilepsi-di-indonesia.html (Accessed on February 7, 2018).

Kaczorowska-Hac B, Matheisel A, Maciejka-Kapuscinska L, 2012. Anemia secondary to valproic acid therapy in a 13-year-old boy: $A$ case report. J Med Case Rep, 6: 1-4.

Kompally V, Ananthula K, Adla N, 2015. Prospective observational study of sodium valproate in seizure control and associated adverse drugs reaction in pediatric population. IOSR-JDMS, 14(11): 28-34.

Kumar SV, Radhika Y, Vijayakumar G, 2014. Therapeutic drug monitoring of valproic acid in pediatric epileptic patients. Int Bulletin Drug Res, 1(1): 11-18.

Mehmood T, Saleem M, Shah SSH, 2014. Frequency of valproate induced thrombocytopenia in epileptic children. JUMDC, 5(2): 52-56.

Nasreddine W, Beydoun A, 2008. Valproate-induced thrombocytopenia: A prospective monotherapy study. Epilepsia, 49(3): 438-445.

Nasrullah M, Saleem K, Zaheer M, 2015. Thrombocytopenia in epileptic patients on valproic acid. PJMHS, 9(1): 24-25.

NICE, 2012. Epilepsies: Diagnosis and management. Available from: https://www.nice.orguk/guidance/cg137 (Accessed on February 7, 2018).

Nordli DR, 2017. The role of electroencephalography in the diagnosis of pediatric epilepsy. In: Peloock JM, Nordli DR, Sankar R, Wheless JW, editors. Pediatric epilepsy: Diagnosis dan therapy. $4^{\text {th }}$ edition. New York: Demos Medical Publishing, pp: 239-245.
Star K, Edwards R, Choonara I, 2014. Valproic acid and fatalities in children: A review of individual case safety reports in vigibase. Plos One, 9(10):1-8.

Suwarba IGN, 2011. Insidens dan karakteristik klinis epilepsi pada anak. Sari Pediatri, 13(2): 123-128.

Tjandrajani Q, Widjaja JA, Dewanti A, 2012. Karakteristik kasus epilepsi di rumah sakit anak dan bunda harapan kita pada tahun 2008-2010. Sari Pediatri, 14(3): 143-146.

Verroti A, Scaparrotta A, Grosso S, 2014. Anticonvulsant drugs and hematological disease. Neurol Sci, 35(7): 983-993.

WHO, 2006. Sodium valproate in childhood epilepsy. WHO. Available from: http://archives.who.int/eml/expcom/expcom15/applications/ paediatrics/formulations/Sodiumvalproate.pdf (Accessed on February 7, 2018).

Citation: Putri Y, Mahalini DS, Suwarba IGNM, 2019. The hematology profiles of children affiliated with epilepsy at Sanglah Hospital after receiving valproic acid therapy. Int Res J M ed M ed Sci, 7(3): 105-110. 